Al-Tijary

Jurnal Ekonomi dan Bisnis Islam

2020, Vol. 5, No. 2, Hal. 139 - 157

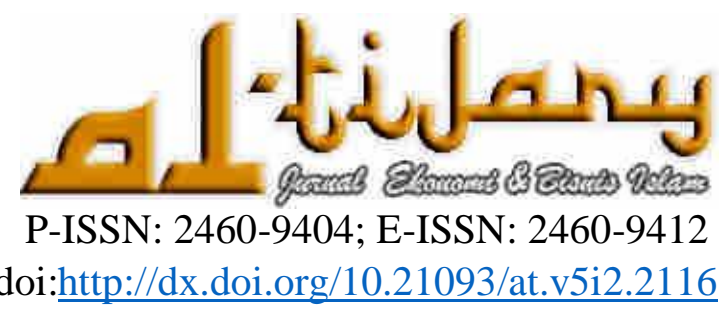

\title{
Peranan Media Sosial Sebagai Agen Sosialisasi Halal dalam Membangun Kesadaran Halal: Studi Netnografi
}

\author{
Miftakhul Khasanah \\ Universitas Muhammadiyah yogyakarta \\ miftakhulkhasanah@umy.ac.id
}

\begin{abstract}
This study aims to determine public behavior related to the use of social media as a source of information and knowledge about halal and the role of social media and its function as an agent of socialization to transfer knowledge and information about halal and build halal awareness in the community. This research was conducted with a Netnographic study. Netnography is an interpretive approach to study consumer behavior from various cultures and communities in cyberspace or the Internet. This approach is also referred to as "digital ethnography" or "virtual ethnography". This study uses the 'halal corner' virtual community account as the object of study and data source to observe the process of transferring halal information and knowledge in shaping halal awareness in the community. This research found that social media acts as an agent for halal socialization and plays a role in shaping halal awareness of Muslim communities.
\end{abstract}

Keywords: halal awareness, halal socialization agent, social media, netnograph

\section{PENDAHULUAN}

Indonesia sebagai negara dengan tingkat populasi Muslim terbesar di dunia yaitu sebesar 215 juta Muslim (tahun 2015) mewakili 13 persen dari populasi Muslim dunia. Dengan populasi muslim yang besar tersebut Indonesia berpotensi menjadi pasar industry terbesar produk halal di dunia.

Menurut laporan Global Islamic Economy Report (GIEI) 2018/2019, Total konsumsi Indonesia di seluruh sektor ekonomi Islam pada tahun 2017 adalah sebesar US \$218,8 miliar. GIEI membagi industri dan bisnis halal ini menjadi 6 sektor yaitu sektor makanan (halal food), keuangan Islam (Islamic Finance), pariwisata syariah (halal travel), sektor fashion syariah (modest fashion), media dan rekreasi (budaya) yang sesuai syariah (halal media dan recreation), obat-obatan dan kosmetik halal (halal pharmaceuticals and cosmetics).

Meskipun mayoritas penduduk Indonesia muslim dan konsumen muslim dilindungi oleh pemerintah melalui LPPOM MUI terkait dengan pelabelan dan informasi produk halal, akan tetapi saat ini kesadaran masyarakat untuk memilih, membeli dan mengkonsumsi produkproduk halal masih rendah (Kurniawati \& Savitri, 2019; Rohmatun \& Dewi, 2017; Yasid, Farhan, \& Andriansyah, 2016). Perilaku kaum muslim dalam mengkonsumsi produk halal sesungguhnya tergantung dari kesadaran dan pengetahuan yang dimiliki terkait dengan halal dan haram, dan juga terkait dengan faktor religiusitas yang dimiliki (Bukhari et al., 2019).

Jurnal Ekonomi dan Bisnis Islam | 139 
Disamping itu, dibutuhkan dukungan internal dari setiap diri individu dalam membangun dimensi religiusitasnya melalui peningkatan keimanan dan ketakwaan kepada Allah SWT, untuk lebih mengaktualisasikan keputusan dalam mengkonsumsi makanan halal, serta berinisiatif untuk turut melakukan pengawasan diri maupun lingkungan atas makanan halal yang terdapat di pasaran (S. Soesilowati, 2009).

Istilah halal sangat terkait dengan religiusitas umat Islam. Islam mengharuskan orang untuk mengkonsumsi makanan halal. Halal atau tidaknya makanan yang dikonsumsi tergantung dari pengetahuan yang dimiliki seorang muslim terkait dengan halal tidaknya suatu produk (Nurhayati \& Hendar, 2019). Sehingga pengetahuan tentang halal-haram seharusnya dimiliki oleh setiap muslim.

Pengetahuan halal (halal knowledge) setiap muslim berbeda-beda tergantung akan banyak hal, salah satunya adalah dari hasil pembelajaran baik secara formal maupun informal. Kemampuan dan kemauan untuk menyerap pengetahuan selain tergantung pada individu itu sendiri juga tergantung pada siapa yang mengajarkan pengetahuan tersebut. Peranan media menjadi salah satu hal yang penting dalam rangka menyebarluaskan informasi dan pengetahuan dalam rangka membangun kesadaran halal. Media sosial dalam hal ini bisa menjadi salah satu agen/perantara dalam menyebarkan pengetahuan dan menciptakan kesadaran halal.

Menurut Fuller dan Jacobs (1973) dalam Sunarto, media sosial internet merupakan salah satu agen sosialisasi yang berperan sebagai alat dalam proses komunikasi massa, karena media sosial internet mampu menjangkau khalayak yang lebih luas dan relatif lebih banyak dan heterogen (Sunarto, 2004)., Hasan menyatakan pentingnya media baik online maupun konvensional untuk berperan serta dalam memberikan edukasi dan menciptakan kesadaran halal di kalangan konsumen Muslim (Hasan, 2016). Media sosial adalah media komunikasi dan informasi yang dapat melakukan penyebaran informasi secara masif dan dapat diakses oleh masyarakat secara massal.

Upaya peningkatan kesadaran masyarakat muslim perlu didukung dengan adanya penyebarluasan informasi dan edukasi yang aktual dan tersebar luas kepada masyarakat secara intensif, berkelanjutan, dan mudah di akses. Informasi dan pengetahuan halal akan sangat efektif dan dan mudah diterima dengan penyebaran melalui media sosial, hal ini bertujuan agar dimensi religiusitas, khususnya dedikasi dan kognisi dengan latar belakang pendidikan agama yang dimiliki umat Islam dapat dioptimalkan dalam hubungannya dengan keputusan mengkonsumsi produk halal (S. Soesilowati, 2009).

Kurangnya kesiapan Indonesia bersaing dalam pasar produk halal disebabkan karena masih lemahnya kesadaran masyarakat akan pentingnya produk halal (Kurniawati \& Savitri, 2019), kurangnya pengetahuan dan pemahaman tentang produk halal inilah yang menyebabkan kurangnya kepedulian masyarakat terhadap makanan halal. Jika kesadaran dan kepedulian masyarakat akan produk makanan halal rendah maka produsen tidak akan berusaha untuk mendapatkan sertifikasi halal. Tetapi, jika kesadaran masyarakat tinggi, mereka akan cenderung membeli produk yang bersertifikat halal dan produsen akan berlomba untuk mendaftarkan produknya agar mendapatkan sertifikat halal. Berdasarkan latar belakang diatas penelitian kali ini dilakukan untuk mengetahui sejauh mana peranan media sosial dalam meningkatkan kesadaran halal. Penelitian ini akan menjelaskan sejauh mana peranan media sosial dalam posisinya sebagai agen sosialisasi halal berdasarkan studi netnography. 


\section{KAJIAN PUSTAKA \\ Halal Dan Haram}

Kata "halal" dan "haram" merupakan istilah Alquran dan digunakan diberbagai tempat dengan konsep yang berbeda, dimana sebagian besar berkaitan dengan produk makanan dan minuman. Halal sendiri didefinisikan sebagai segala sesuatu yang di perbolehkan oleh syariat untuk (i) dilakukan, (ii) digunakan, atau (iii) diusahakan, karena telah terurai tali atau ikatan yang mencegahnya atau unsur yang membahayakannya dengan disertai perhatian dari cara memperoleh dan mendapatkannya, dan bukan dari hasil muamalah yang dilarang (Ali, 2016).

Dasar yang digunakan untuk menunjukkan keharusan mengonsumsi makanan dan minuman, tumbuhan dan binatang/hewan yang telah halal lagi thayyib (baik) tercantum dalam Alquran dan Hadist, seperti perintah untuk mengkonsumsi dan memanfaatkan yang halal yaitu: Qs. al-Baqarah [2]: 168 dan 172, Q.s. al-Nahl [16]: 412, al- Mâ'idah [5]: 87 dan 88, al-Anfâl [8]: 69, al-Nahl [16]: 114. Dalam ayat-ayat ini kata "halal" menjadi dasar perintah mengonsumsi makanan dan minuman yang halal dan thayyib (Ali, 2016).

Dari sisi bahasa, haram adalah dilarang/terlarang atau tidak diizinkan sedangkan dari sisi istilah, menurut Yûsuf al-Qarâdhawî, haram adalah segala sesuatu yang dilarang oleh Allah SWT untuk dilakukan dengan akibat yang tegas, setiap orang yang menentangnya akan berhadapan dengan siksaan Allah di dunia dan akhirat. Menurut al-Qarâdhawî wilayah keharaman dalam syariat Islam sangatlah sempit, sebaliknya, wilayah kehalalan terbentanglah sangat luas. Karena nas (nash) yang datang dengan pengharaman sedikit sekali jumlahnya. Selain itu, sesuatu yang tidak ada nash yang mengharamkan atau menghalalkannya, ia akan kembali kepada hukum asalnya, yaitu boleh (Qardhawi, 1980).Berdasarkan hadist yang diriwayatkan oleh HR. Bukhori \& Muslim, Sesuatu yang halal itu sudah jelas, demikian pula yang haram, namun diantara keduanya ada perkara syubhat. Rasulullah saw. bersabda, "Sesungguhnya yang halal itu jelas dan yang haram itu jelas (Zulaekah \& Kusumawati, 2005)

Sedangkan secara terminology syubhat adalah sesuatu yang tidak jelas kehalalan dan keharamannya karena banyak manusia yang tidak mengetahui hukumnya. Adapun ulama mereka dapat mengetahui hukum dari nas atau qiyâs atau sebagainya, apabila seseorang meragukan sesuatu apakah halal atau haram sementara tidak ada nas dan ijmak sebagai hasil ijtihad mujtahid lalu mendapatkan dalil syar'i-nya lalu dijumpainya halal maka ia menjadi halal, tetapi terkadang ada dalilnya, namun tidak tertutup kemungkinan keraguan (ihtimâl) yang jelas maka lebih utama bersikap wara' dengan meninggalkannya (Ali, 2016).

Halal yang dimaksud dalam penelitian ini adalah halal secara umum, bisa berupa produk makanan, bisa berupa halal lifestyle dan pengetahuan atau informasi terkait halal.

\section{Kesadaran Halal (Halal Awareness)}

Beberapa cendekiawan telah membedakan tingkatan kesadaran menjadi beberapa tingkat yaitu: (1) tingkat kesadaran yang lebih tinggi; (2) kesadaran tingkat rendah; (3) alam bawah sadar; (4) tidur dan mimpi (tingkat rendah kesadaran), dan (5) ketidaksadaran (proses tidak sadar / tidak sadar).

Orang yang berbeda dapat memiliki tingkat kesadaran yang berbeda. Menurut seorang psikolog, tingkat kesadaran berarti kesadaran akan peristiwa luar dan sensasi internal yang terjadi dengan kondisi penuh gairah (King, 2008). Kesadaran dalam konteks umum secara literal berarti memiliki pengalaman tentang sesuatu dan/atau mengetahui dengan baik tentang apa yang terjadi sekarang dalam makanan, minuman dan produk halal lainnya. Oleh karena itu, kesadaran dalam konteks halal dapat dikonseptualisasikan sebagai suatu proses penyediaan informasi untuk meningkatkan tingkat kesadaran tentang apa yang dikonsumsi dan digunakan 
oleh Muslim (Ambali \& Bakar, 2014). Merujuk pada Ambali dan Bakar, kesadaran halal dapat didefinisikan sebagai memiliki minat atau pengalaman khusus atau memiliki informasi yang cukup tentang sesuatu makanan, minuman dan produk halal. Dengan kata lain kesadaran adalah bagian dasar dari keberadaan manusia, yang menggambarkan persepsi manusia dan reaksi kognitif terhadap kondisi apa yang mereka makan, minum dan gunakan (Ambali \& Bakar, 2014). Sehingga dapat disimpulkan kesadaran halal merupakan persepsi dan reaksi kognitif seseorang dalam mengetahui, memahami, merasakan dan memilih produk halal baik makanan maupun minuman berdasarkan informasi tentang halal yang didapat seseorang secara sadar.

Golnaz et al. dalam Aziz dan Chok, menemukan dalam penelitian mereka bahwa kesadaran akan prinsip halal dan produk makanan halal ditentukan oleh sikap positif (Aziz \& Chok, 2013). Sesuai dengan teori TPB (Theory of Planned Behaviour), konsumen yang memiliki sikap yang baik akan melakukan perilaku untuk mengkonsumsi atau membeli produk halal. Dalam konteks penelitian ini, sikap positif adalah persepsi yang menguntungkan dalam konsep halal dan kesadaran halal.

\section{Pengetahuan Halal (Halal Knowledge)}

Pengembangan produk dalam perspektif Islam harus divisualisasikan secara berbeda dibandingkan dengan pemikiran Barat. Dalam Islam, unsur-unsur moral dan transenden harus sangat ditekankan dalam proses produksi dan pengambilan keputusan, dan harus berdasarkan prinsip-prinsip etika bisnis. Harus ditunjukkan bahwa praktik dan barang komersial tertentu dilarang oleh Islam. Islam menggabungkan unsur-unsur moral dan transendental dalam proses produksi dan pemasaran dengan prinsip-prinsip etika bisnis Islam sebagai panduan (Abuznaid, 2012).

Hal ini merupakan bagian dari pengetahuan yang harus dipahami oleh konsumen ketika mereka menginginkan produk halal. Pengetahuan produk menjadi bagian penting dari perilaku konsumen sehingga menjadi bagian yang menarik dalam penelitian ini. Pengetahuan produk terkait dengan pengetahuan tentang produk yang dikenal oleh konsumen (Brucks, 1985); Pengetahuan produk tergantung pada pengetahuan subjek atau pengetahuan yang dirasakan; pengetahuan objektif; dan pengetahuan berbasis pengalaman (Lin \& Chen, 2006).

Pengetahuan produk melibatkan pengetahuan tentang manfaat produk dan pengetahuan tentang kepuasan yang diberikan produk kepada konsumen. Ini melibatkan pengetahuan tentang karakteristik atau atribut produk (fisik dan abstrak), pengetahuan tentang pembelian mengenai kapan dan apakah produk tersebut akan dibeli dan diketahui penggunaannya, termasuk cara produsen tersebut termasuk konsumsi atau konsumsi produk tersebut sehingga fungsi produk dengan benar (Nurhayati \& Hendar, 2019). Pengetahuan produk juga terkait dengan keahlian dan keakraban (familiar) dengan produk (Alba \& Hutchinson, 1987).

Nurhayati dan Hendar, menyatakan bahwa pengetahuan produk halal dapat diartikan sebagai kumpulan berbagai macam informasi tentang produk halal, yang meliputi kategori produk, merek, terminologi produk, atribut atau fitur produk, harga produk, tempat dan waktu penjualan, cara menggunakan dan mempercayai produk halal Pengetahuan tentang produk halal juga terdiri dari pengetahuan tentang di mana dan kapan konsumen membeli produk halal dan juga siapa yang menjual produk halal (Nurhayati \& Hendar, 2019).

Model sosialisasi konsumen umumnya berasumsi bahwa orang mengembangkan pola pemikiran dan tindakan seperti itu karena hasil dari interaksi mereka dengan "sesuatu yang signifikan" yang disebut sebagai agen sosialisasi, dan sebagian yang lain disebabkan karena perubahan biologis atau kognitif-psikologis internal (Moschis \& Churchill, 1978). 
Sosialisasi adalah sebuah proses penanaman atau transfer kebiasaan atau nilai dan aturan dari satu generasi ke generasi lainnya dalam sebuah kelompok atau masyarakat. Sejumlah sosiolog menyebut sosialisasi sebagai teori mengenai peranan (role theory) (Anon, 2019). Perubahan ini memengaruhi kemampuan individu untuk belajar, dan mereka menciptakan kebutuhan yang secara langsung atau tidak langsung (dengan memengaruhi interaksi seseorang dengan agen) dapat memengaruhi pembelajaran konsumen. Selain itu, sosialisasi konsumen dipengaruhi oleh beberapa faktor struktural sosial, misal kelas sosial, ras, jenis kelamin yang secara langsung maupun tidak langsung dapat mempengaruhi pembelajaran dan pengetahuan konsumen (Moschis \& Churchill, 1978).

Proses sosialisasi akan berjalan lancar apabila pesan-pesan yang disampaikan oleh agen-agen sosialisasi itu tidak bertentangan atau selayaknya saling mendukung satu sama lain. Akan tetapi, di masyarakat, sosialisasi dijalani oleh individu dalam situasi konflik pribadi karena dikacaukan oleh agen sosialisasi yang berlainan (Komariah \& Subekti, 2016).

Dari pemaparan diatas dapat dikatakan bahwa ditengarai ada kegiatan sosialisasi yang membuat kesadaran akan halal itu timbul. Sosialisasi halal adalah proses dimana individu mengembangkan kognisi dan perilaku yang berhubungan dengan halal baik itu dalam hal konsumsi, gaya hidup maupun perilaku.

\section{METODE PENELITIAN}

Penelitian ini dilakukan dengan menggunakan metode netnografi dengan melakukan observasi dan wawancara online. Netnografi merupakan komunikasi menggunakan komputer atau computer-mediated communications (CMC), yaitu komunikasi yang terjadi melalui komputer atau jaringan. CMC tersebut termasuk di dalamnya ialah forums, postings, instant message, email, chat-room, dan mobile text message (Kozinets, 1998). Jadi CMC merupakan sumber bagi para peneliti untuk mengumpulkan data etnografi mereka, data yang merepresentasikan fenomena budaya dan masyarakat (Purwanto \& Ilhalauw, 2017). Kegunaan netnografi adalah untuk dapat mengidentifikasi tren industri dan pilihan dari konsumen; membantu brand dalam mengembangkan dan meningkatkan kualitas produk; serta dalam mengembangkan strategi pemasarannya (Nasrullah, 2017). Pengumpulan data dilakukan dengan pendekatan observasi-partisipasi dan wawancara secara online. Terdapat minimal dua elemen yang penting dalam proses pengumpulan data ini, yaitu: data yang disalin langsung oleh peneliti dari komunikasi yang ada dalam objek penelitiannya, dan data yang dideskripsikan oleh peneliti dari pengamatannya tentang; komunitas itu sendiri, anggota, dan interaksi yang ada. Subjek dalam penelitian ini adalah komunitas-komunitas virtual tentang halal di media sosial yaitu Instagram dan Facebook sedangkan penentuan Objek Penelitian yang diteliti, dilakukan dengan melakukan tahapan penelitian sebagai berikut (1) Mengumpulkan informasi melalui komunitas-komunitas Whats App Grup (WaG) dengan menyebarkan pertanyaan tentang media apa yang paling disukai dalam memberikan informasi terkait Halal; (2) berdasarkan informasi yang didapat maka diperoleh 2 media sosial yang paling disukai yaitu Facebook dan Instagram; (3) melakukan pencarian komunitas-komunitas virtual yang terkait dengan 'halal' di halaman Facebook dan Instagram dengan menggunakan kata kunci : "halal”, "infohalal"; (4) Melakukan pemilihan komunitas virtual yang dipakai sebagai objek penelitian dengan beberapa kriteria, yaitu komunitas virtual yangmempunyai data yang detail dan banyak, mempunyai jumlah pengikut (followers) terbanyak, terdapat interaksi aktif antar entitas yang berada dalam komunitas tersebut dengan intensitas tinggi; komunitas virtual tersebut aktif di media sosial yang ditunjukkan dengan periode jangka waktu dan jumlah postingan yang diunggah. Yang kemudian Komunitas Halal Corner terpilih 
menjadi objek penelitian ini (Lampiran 1). Pengumpulan data dilakukan dengan melakukan pencarian data komunitas virtual di Media Sosial Facebook dan Instagram. Pencarian data komunitas virtual tersebut dilakukan dengan menggunakan kata kunci dan Hashtag (Instagram) (lampiran 2). Selanjutnya data yang dikumpulkan dari CMC dipilah-pilah dengan melakukan koding, yang dilakukan dengan menggunakan kata kunci. Selain itu dilakukan wawancara online dengan menggunakan purposive sampling dengan responden yang merupakan pengikut aktif di Instagram 'halal corner' untuk melakukan triangulasi sumber. Terakhir dilakukan analisa dan kesimpulan hasil.

\section{HASIL DAN PEMBAHASAN}

Penelitian tentang peranan media sosial dan fungsinya sebagai agen sosialisasi halal dilakukan dengan menggunakan akun 'halalcorner' di Instagram sebagai objek penelitian dengan periode antara bulan Januari 2019 sampai dengan Juli 2019. Sampai dengan Akhir Juli 2019 akun 'halalcorner' di Instagram mempunyai 80.700 pengikut (followers). Dengan total jumlah postingan 895 postingan.

Penelitian difokuskan kepada postingan yang diunggah oleh akun 'halalcorner' atas dasar banyaknya interaksi terhadap suatu postingan. Dari hasil observasi yang dilakukan terdapat 7 postingan di akun 'halalcorner' di Instagram yang dipakai sebagai objek kajian berdasarkan banyaknya interaksi (Lampiran 3) yaitu (1) dampak mengkonsumsi barang haram; (2) kehalalan popok bayi dan masa kadaluarsa; (3)rum dan essence rhum dinyatakan haram oleh mui; (4) gambar skema produk dari babi dan produk turunannya; (5) berbagai macam istilah daging babi dalam berbagai makanan (komposisi makanan); (6) hukum bacon dan penamaan bacon; (7) kehalalan kopi terkait dengan adanya bahan tambahan.

Postingan -postingan yang diunggah oleh akun 'halalcorner' tersebut saling berkaitan, hal ini teramati dari komentar-komentar yang ada di setiap postingan. Berikut masing-masing postingan dan pengaruhnya terhadap netizen.

1. Dampak mengkonsumsi barang halal

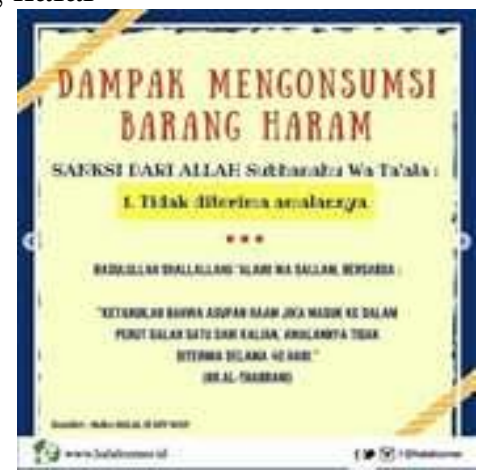

\section{Gambar 1. Postingan Dampak Mengkonsumsi Barang Halal}

Kelebihan postingan di Instagram adalah memanjakan para netizen dengan konten visual berupa foto dan video serta bisa dilengkapi keterangan (caption). Postingan ini diunggah pada tanggal 7 Januari 2019. Berdasarkan komentar yang masuk umumnya netizen berterimakasih dengan informasi yang diberikan, dan meminta izin untuk membagikan (share) postingan tersebut, sedangkan Hashtag yang dipergunakan yaitu: \#halalismyway \#halalcornerlovers \#halalismylife \#halalislifestyle \#infohalal \#artikelhalal \#halalcorner \#cariinfohalal \#halalindonesia \#indonesiahalal \#produkhalal \#pasarhalal \#industrihalal. 
2. Kehalalan Popok Bayi dan Masa kadaluarsa

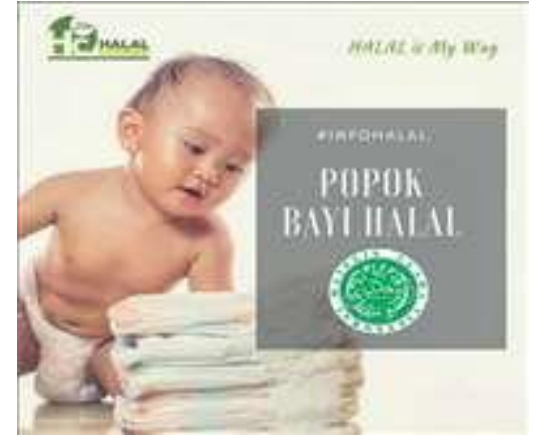

\section{Gambar 2. Postingan Tentang Kehalalan Popok Bayi}

Postingan ini diunggah pada tanggal 16 Januari 2019, postingan ini mempunyai 214 komentar, dengan pertanyaan terbanyak tentang titik kritis dari popok bayi, dan pertanyaan tentang produk-produk popok bayi dan kehalalannya yang belum ada informasinya.

3. Rum dan Essence Rhum dinyatakan Haram oleh MUI

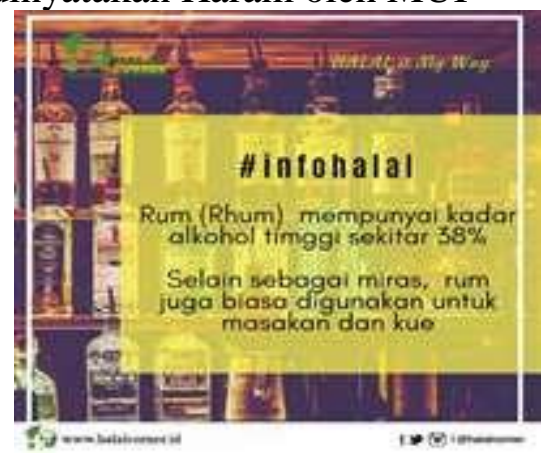

Gambar 3. Postingan Tentang Keharaman Rum dan Essence Rhum

Banyak yang belum tahu informasi tentang rum dan essence rum. Postingan ini diunggah pada tanggal 12 Maret 2019. Pertanyaan yang ditanyakan berkisar tentang adakah rum yang halal? Kenapa ada produk yang mengandung rum tetapi mengklaim kalau produk tersebut halal?. Hashtag yang dipergunakan adalah \#halalismyway \#halalcornerlovers \#halalismylife \#artikelhalal \#cintahalal \#indonesiahalal \#halalindonesia \#produkhalal \#halalislifestyle \#Indonesiasadarhalal \#Indonesiamelekhalal.

4. Gambar skema produk dari Babi dan produk turunannya

Postingan ini diunggah pada tanggal 28 Maret 2019 dan disukai oleh 2650 netizen dengan 150 komentar. Terlihat dari komentar yang masuk banyak yang tidak tahu produkproduk turunan dari babi yang sangat banyak dan hampir semua bagian dari babi bisa dipakai sebagai bahan baku bermacam produk. Hashtag yang digunakan yaitu \#halalismyway \#halalcornerlovers \#halalismylife \#artikelhalal \#cintahalal \#indonesiahalal \#halalindonesia \#produkhalal \#halalislifestyle \#Indonesiasadarhalal \#Indonesiamelekhalal. 


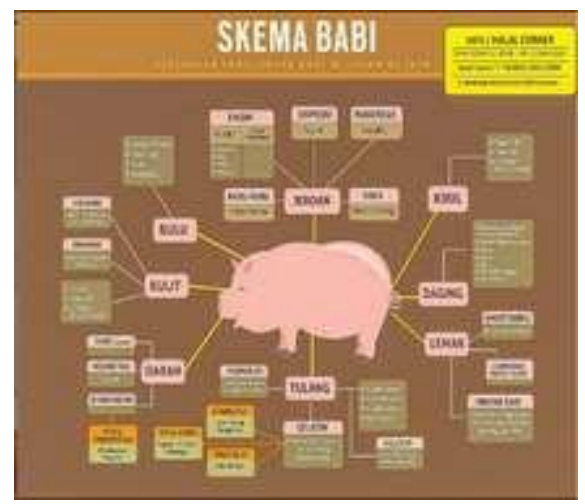

\section{Gambar 4. Postingan Tentang Produk Babi Dan Turunannya}

5. Berbagai macam Istilah daging Babi dalam berbagai makanan (komposisi makanan)

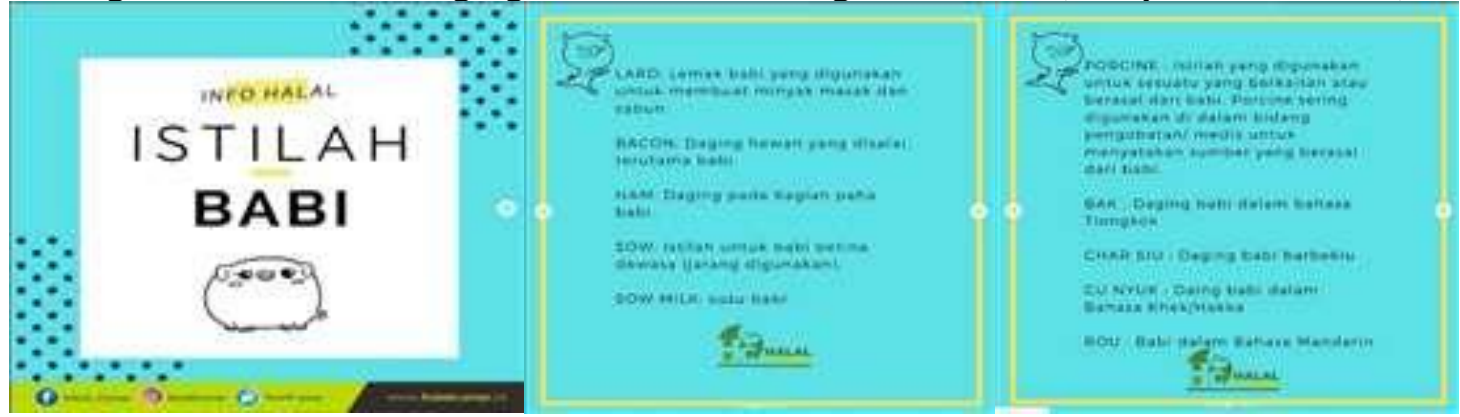

\section{Gambar 5. Postingan Tentang Berbagai Penamaan Babi}

Postingan ini diunggah pada tanggal 30 Maret 2019 , disukai oleh 4317 netizen dan ada 154 komentar. Didalam postingan ini terdapat perbedaan istilah tentang ham dan bacon. Kemudian admin menindaklanjuti dengan postingan tertanggal 1 Juni 2019 tentang hukum bacon dan penamaan bacon. Hashtag yang digunakan : \#halalismyway \#halalcornerlovers \#halalismylife \#artikelhalal \#cintahalal \#indonesiahalal \#halalindonesia \#produkhalal \#halalislifestyle \#Indonesiasadarhalal \#Indonesiamelekhalal.

6. Hukum bacon dan penamaan bacon
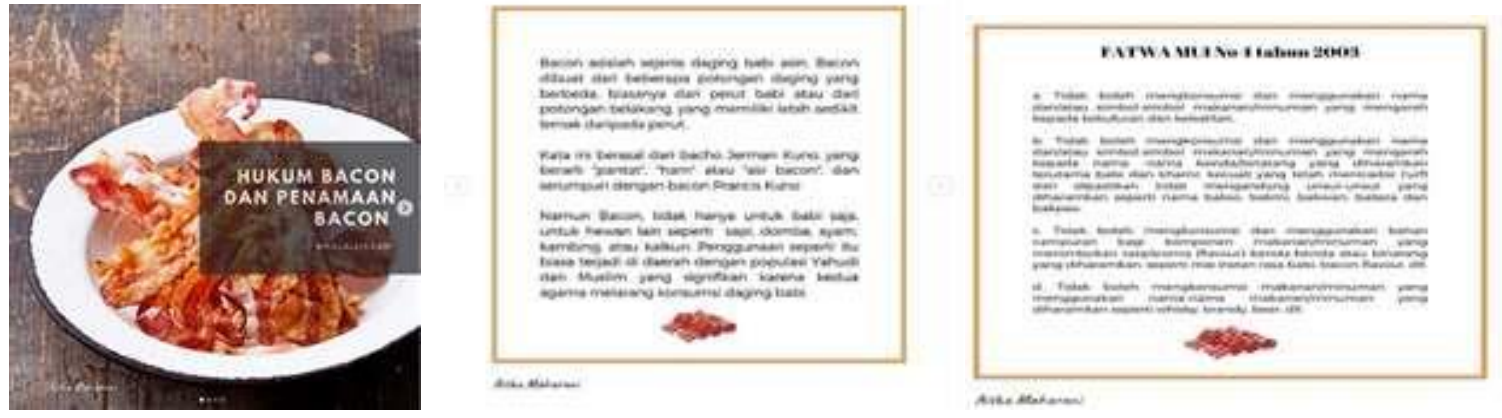

Gambar 6. Postingan Tentang Hukum bacon dan penamaan bacon

Postingan tentang Hukum Bacon dan Penamaan Bacon ini diunggah pada tanggal 21 Juni 2019. Terkait dengan postingan tentang penamaan istilah babi pada berbagai makanan 
dan adanya perbedaan istilah. Hashtag yang digunakan : \#halalismyway \#halalcornerlovers \#halalismylife \#artikelhalal \#cintahalal \#indonesiahalal \#halalindonesia \#produkhalal \#halalislifestyle \#Indonesiasadarhalal \#Indonesiamelekhalal.

7. Kehalalan kopi terkait dengan adanya bahan tambahan

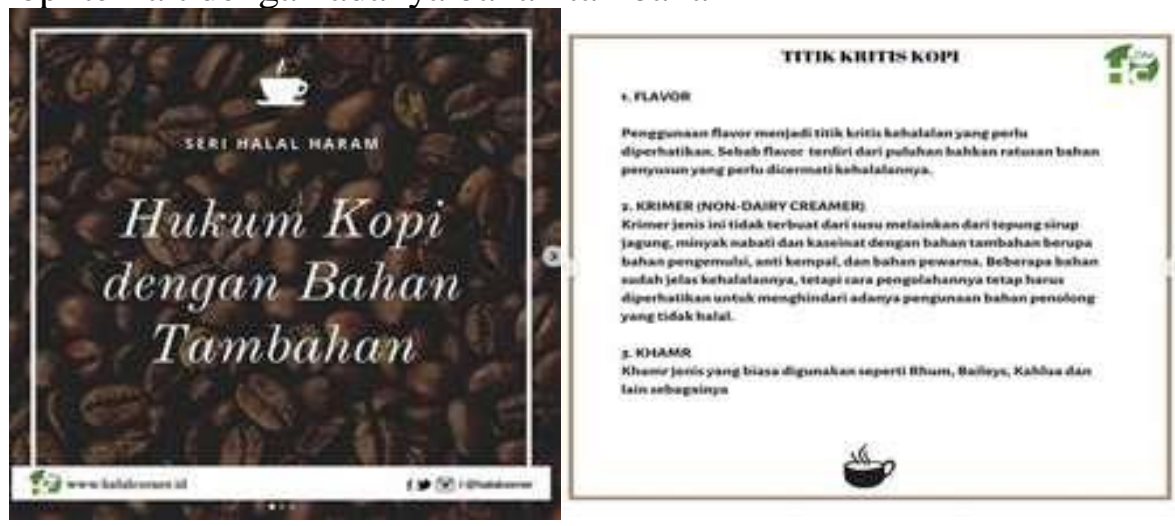

\section{Gambar 6. Postingan Tentang Titik Kritis Kopi}

Postingan ini diunggah pada tanggal 9 Juli 2019. Postingan ini banyak dibagi oleh netizen dalam bentuk screen shoot, dan dibagikan oleh ribuan netizen di media sosial facebook. Banyak netizen yang belum mengetahui titik kritis produk kopi. Titik kritis kehalalan produk adalah tahapan-tahapan produksi dimana ada kemungkinan suatu produk menjadi haram. Bisa berkaitan dengan bahan baku, proses produksi, alat yang dipergunakan ataupun dalam proses perpindahan produk dari produsen ke konsumen (delivered).

Berdasarkan hasil observasi dengan menggunakan data CMC dari postingan-postingan yang ada dan wawancara online yang dilakukan maka setelah dilakukan proses koding maka hasil penelitian terangkum dalam tabel 1 .

Tabel 1. Analisa Hasil Penelitian

\begin{tabular}{|l|l|}
\hline \multicolumn{1}{|c|}{ Kata Kunci } & \multicolumn{1}{c|}{ Keterangan } \\
\hline Informasi halal & $\begin{array}{l}\text { Menambah informasi baru, banyak produk yang dianggap halal ternyata } \\
\text { belum. Membuka wawasan tentang halal }\end{array}$ \\
\hline Pengetahuan tentang halal & $\begin{array}{l}\text { Banyak pengetahuan yang didapat terkait halal. Halal dan haram tidak saja } \\
\text { terkait dengan makanan dan minuman tetapi juga dengan semua produk } \\
\text { yang kita gunakan }\end{array}$ \\
\hline label halal & $\begin{array}{l}\text { Harus selalu memperhatikan adanya label halal resmi yang dikeluarkan } \\
\text { pemerintah dalam hal ini adalah MUI. Belum tentu produk dengan label } \\
\text { halal sudah pasti halal karena terkait dengan tanggal kadaluarsa dari label } \\
\text { halal tersebut }\end{array}$ \\
\hline label halal palsu & $\begin{array}{l}\text { Harus waspada dan hati-hati dengan label halal, karena ternyata banyak } \\
\text { produk yang menggunakan label halal palsu, ketika di cek di web MUI } \\
\text { tidak terdaftar. Ada juga label halal yang sudah kadaluarsa lama dan } \\
\text { belum diperpanjang }\end{array}$ \\
\hline kesadaran tentang Halal & $\begin{array}{l}\text { Umumnya kesadaran halal semakin meningkat ketika terpapar informasi } \\
\text { dari media sosial. Yang awalnya cuek dengan label halal menjadi lebih } \\
\text { perhatian dan memperhatikan komposisi terutama komposisi makanan dan } \\
\text { minuman yang akan kita konsumsi }\end{array}$ \\
\hline
\end{tabular}

Sumber: Data primer diolah 


\section{PEMBAHASAN}

Seiring dengan perkembangan teknologi informasi yang sangat pesat di era 4.0 ini membuat media sosial menjadi agen sosialisasi yang utama. Media massa mempunyai kekuatan yang besar dalam memberikan informasi yang mengarahkan pola berfikir dan perilaku seseorang (Solihat, 2008). Peranan media sosial dalam melakukan komunikasi dan penyebaran informasi sudah tidak diragukan lagi. Berbagai penelitian menyebutkan bahwa media sosial online sering dipergunakan dalam sosialisasi terkait dengan politik (Abdillah, 2014; Sandra, 2013), kesehatan (Komariah \& Subekti, 2016), juga pemasaran (Siswanto, 2013; Tajuddin \& Manan, 2017)

Informasi tentang halal yang didapat dari media sosial tersebut akan menstimulus proses atensi dalam pembentukan kesadaran halal (Birda, Kamid, \& Rusdi, 2016). Dan atau informasi tentang halal tersebut akan merangsang proses recall knowledge (mengingat pengetahuan ) yaitu proses pengambilan informasi tentang halal yang telah ada (Maharani \& Mustika, 2016). Berkaitan dengan kesadaran halal, umumnya pengikut (followers) akun Instagram 'halalcorner' mempunyai kesadaran halal yang sudah terbentuk, tetapi ada juga yang kesadaran halal mereka terbentuk dari postingan yang diunggah oleh akun 'halalcorner'. Kesadaran halal dapat diartikan sebagai kemampuan konsumen untuk mengenali dan mengingat produk halal dalam situasi yang berbeda.

Kesadaran halal memiliki dua dimensi, yaitu, mengingat halal dan pengakuan halal. Mengingat halal berarti bahwa ketika konsumen melihat kategori produk, mereka dapat mengingat produk dengan nama merek produk dan halal yang benar. Sedangkan pengenalan halal berarti konsumen memiliki kemampuan untuk mengidentifikasi produk halal dengan benar ketika mereka melihat atau mendengarnya (Nurhayati \& Hendar, 2019).

Jika kesadaran halal sudah ada dan terbentuk umumnya mereka membutuhkan informasi yang simple dan mudah di dapat. Biasanya jika kita akan mencari kehalalan suatu produk harus menyusuri satu per satu list / daftar produk yang terdaftar halal di MUI dan itu membutuhkan waktu yang cukup lama, sehingga mereka lebih suka cara yang simple yaitu dengan mencari postingan tentang suatu produk dan menyimpan informasi tersebut kedalam fitur simpan dalam media sosial.

Pada umumnya saat ini banyak pihak telah berkontribusi pada peningkatan kesadaran untuk memenuhi kebutuhan dan keinginan pasar, dan secara sistematis memberikan informasi kepada struktur pasar yang komprehensif. Hal ini tidak hanya melibatkan pemasok, tetapi juga merupakan informasi bagi para pengguna akhir. Oleh karena itu, situasi tersebut menghasilkan kesadaran konsumen akan keberadaan lini produk halal yang ditawarkan oleh merek global (Abdul-Talib \& Abd-Razak, 2013).

Media sosial sangat mudah diakses, bahkan setiap waktu dan setiap saat orang akan mudah untuk mendapatkan informasi dan pengetahuan apapun, bahkan jika kita mengikuti (follow) suatu grup atau akun maka kita akan mendapatkan pemberitahuan (notifikasi) jika ada postingan terbaru. Dengan kemudahan akses pada media sosial maka berarti juga kemudahan dalam memperoleh pengetahuan tentang produk halal. Terkait dengan pendapat dari netizen yang mengikuti akun 'halalcorner' menyatakan bahwa informasi yang disajikan sangat lengkap, tidak hanya terkait dengan halal dan haram suatu produk makanan (halal food) tetapi juga terkait dengan produk non-makanan. Biasanya juga disajikan informasi yang berkaitan dengan tanggal kadaluarsa sertifikat halal yang dikeluarkan. Dari sini dapat dikatakan bahwa media sosial juga melakukan proses transfer pengetahuan.

Menurut Jacoby et al pengetahuan konsumen memiliki dua komponen utama yaitu familiar/ keakraban dan keahlian. familiar didefinisikan sebagai seberapa banyak pengalaman 
terkait dengan produk yang telah diakumulasikan oleh konsumen (Jacoby, Troutman, Kuss, \& Mazursky, 1986). Keahlian didefinisikan sebagai kemampuan untuk melakukan tugas yang berhubungan dengan produk dengan sukses. Pengalaman terkait produk didefinisikan pada tingkat paling inklusif. Pengalaman tersebut termasuk paparan iklan, pencarian informasi, interaksi dengan tenaga penjualan, pilihan dan pengambilan keputusan, pembelian, dan penggunaan produk dalam berbagai situasi. Istilah keahlian konsumen juga bisa diartikan luas mencakup struktur kognitif misal keyakinan tentang atribut produk dan proses kognitif, misal keputusan untuk bertindak berdasarkan keyakinan tersebut, yang diperlukan untuk melakukan tugas yang terkait dengan produk.

Dari hasil observasi data dari CMC dan wawancara online diketahui bahwa kesadaran halal lebih meningkat jika berada di luar negeri atau didaerah dimana muslim menjadi minoritas (Ismoyowati, 2015; Soesilowati \& Yuliana, 2013). Hal ini juga ditemukan dalam penelitian ini berdasarkan postingan dan pertanyaan terkait pencarian makanan halal ketika traveling di luar negeri. Selain itu dari hasil observasi tentang grup dan komunitas yang ada di Facebook dan Instagram (lihat Tabel 1. dan Tabel 2. Tentang Komunitas Virtual 'halal' di Media Sosial) banyak komunitas virtual yang menggabungkan antara makanan dan pariwisata (food and traveling). Biasanya kesadaran halal lebih kuat ketika berada di luar negeri terutama negara-negara non muslim, karena produk-produk yang akan dikonsumsi belum tentu halal.

Literatur pemasaran produk halal saat ini kebanyakan membahas produk halal dan Islam memiliki peranan yang dominan dalam proposisi ini. Para peneliti menyajikan paradigma halal sebagai area di mana pola pengambilan keputusan kognitif, afektif dan konatif dipengaruhi oleh minimalisasi resiko. Paradigma halal adalah inti di mana dirasakan pentingnya halal dibawa ke dalam kesadaran Muslim (Wilson \& Liu, 2011).

Media sosial telah bertindak sebagai agen sosialisasi halal karena dari sosial media ini terjadi pertukaran (transfer) ilmu dan informasi terkait dengan kehalalan dan keharaman produk. Didalam komunitas virtual yang mempunyai komunikasi aktif antar entitas akan berdampak positif dalam pertukaran informasi terkait dengan kehalalan produk. Dari hasil observasi data CMC dan wawancara online yang dilakukan, menunjukkan bahwa media sosial memberikan banyak informasi berupa pengetahuan halal, dengan bertambahnya pengetahuan yang didapatkan maka akan berpengaruh terhadap kesadaran halal. Jika merujuk kepada Theory of Planned Behavior (Ajzen, 1991), kesadaran halal akan berpengaruh kepada sikap (Bashir, 2019; Setyaningsih \& Marwansyah, 2019; Soon \& Wallace, 2017). Selanjutnya sikap mempengaruhi perilaku halal, perilaku halal akan membentuk pola hidup halal. Pola hidup halal yang dilakukan dalam kehidupan sehari-hari akan membentuk gaya hidup halal (halal lifestyle).

Kaiser dan Menkhoff dalam penelitiannya menemukan bahwa pendidikan keuangan memiliki pengaruh positif dan signifikan terhadap pengetahuan keuangan dan perilaku keuangan. Proses terbentuknya perilaku yang didasari oleh pengetahuan, kesadaran dan sikap yang positif, maka perilaku tersebut akan bersikap langgeng (Kaiser \& Menkhoff, 2017). Sebaliknya apabila perilaku tersebut tidak didasari oleh pengetahuan dan kesadaran maka tidak akan berlangsung lama (Notoatmodjo, 2003)

Beberapa penelitian menyatakan bahwa ada hubungan antara sosialisasi dan perilaku finansial (Nyota, 2016; Sohn, Joo, Grable, Lee, \& Kim, 2012) Berdasarkan penelitian tentang hubungan antara sosialisasi keuangan dan perilaku keuangan maka pengaruh yang sama antara sosialisasi halal dengan kesadaran dan perilaku halal teramati dalam studi ini. 


\section{PENUTUP}

\section{Kesimpulan}

Peranan media sosial sebagai agen sosialisasi halal menjadi sangat perlu, terkait dengan perubahan pola-pola struktur budaya dan perilaku di masyarakat. Jika dikaitkan dengan perilaku masyarakat pada saat ini dimana internet telah menjadi suatu budaya dan kebiasaan yang tidak dapat dipisahkan dari perilaku masyarakat membuat media sosial menjadi salah satu agen penting dalam rangka sosialisasi informasi dan pengetahuan halal dan menjadi pemantik (trigger) dalam mengunggah kesadaran halal.

Kesadaran halal yang sudah terbentuk akan berpengaruh kepada sikap dan membentuk perilaku halal. Pola hidup halal yang dilakukan sehari-hari akan membentuk gaya hidup halal. Perilaku yang didasari oleh pengetahuan, kesadaran dan sikap yang positif, maka perilaku tersebut akan berlangsung lama.

\section{Saran}

Efektivitas peranan media sosial sebagai agen sosialisasi halal masih bisa digali dengan riset kuantitatif. Ada begitu banyak penelitian terkait dengan halal-haram produk yang bisa dilakukan dengan menggunakan studi netnografi, karena dari studi ethnografi virtual / netnografi ini kita bisa mendapatkan wawasan dan persepsi (insight) yang mendalam dari perilaku dan kesadaran halal dari masyarakat. Bagi pemasar hal ini bisa dijadikan informasi yang berharga dalam kaitannya dengan penyusunan konsep dan strategi pemasaran. Selain itu, kesadaran halal yang tinggi menyebabkan tingkat pembelian produk halal yang tinggi pula sehingga mempengaruhi produsen untuk memproduksi produk yang halal, maka secara ekonomi Indonesia tidak hanya sekedar menjadi market pasar halal saja tetapi juga menjadi produsen produk halal yang diakui dunia.

\section{DAFTAR PUSTAKA}

Abdillah, L. A. (2014). Social-Media as Political Party Campaign in Indonesia. Jurnal Ilmiah MATRIK, 16(01), 1-10.

Abdul-Talib, A., \& Abd-Razak, I. (2013). Cultivating Export Market Oriented Behavior in Halal Marketing: Addressing the Issues and Challenges in Going Global. Journal of Islamic Marketing, 04(02), 187-197.

Abuznaid, S. (2012). Islamic Marketing: Addressing the Muslim Market. An - Najah Univ. J. Res. (Humanities), 26(06), 1473-1503.

Ajzen, I. (1991). The Theory of Planned Behavior. Organizational Behaviour and Human Decision Processes, 50(02), 179-211.

Alba, J. W., \& Hutchinson, J. W. (1987). Dimensions of Consumer Expertise. Journal of Consumer Research, 13(04), 411-454.

Ali, M. (2016). Konsep Makanan Halal dalam Tinjauan Syariah dan Tanggung Jawab Produk Atas Produsen Industri Halal. Ahkam:Jurnal Ilmu Syariah, 16(02).

Ambali, A. R., \& Bakar, A. N. (2014). People's Awareness on Halal Foods and Products: 
Potential Issues for Policy-Makers. In Procedia - Social and Behavioral Sciences. Kuala Lumpur: INHAC.

Annisa, S. (2019). Studi Netnografi Aksi Beat Plastic Pollution Oleh United Nations Environment Di Instagram. Jurnal ASPIKOM, 03(06), 1109-1123.

Anon. (2019). Sosialisasi. Retrieved from https://id.wikipedia.org/wiki/Sosialisasi

Aziz, Y. A., \& Chok, N. V. (2013). The Role of Halal Awareness, Halal Certification, and Marketing Components in Determining Halal Purchase Intention Among Non-Muslims in Malaysia: A Structural Equation Modeling Approach. Journal of International Food \& Agribusiness Marketing, 25(01), 1-23.

Bashir, A. M. (2019). Effect of Halal Awareness, Halal Logo and Attitude on Foreign Consumers' Purchase Intention. British Food Journal, 121(09), 1998-2015.

Birda, A. M., Kamid, \& Rusdi, M. (2016). Proses Atensi Pengetahuan pada Siswa Attention Deficit Hyperactivity Disorder (ADHD) dalam Memecahkan Masalah Matematika Materi Aritmetika Sosial. Edu-Sains: Jurnal Pendidikan Matematika Dan Ilmu Pengetahuan Alam, 05(01), 10-19.

Bukhari, S. F. H., Woodside, F. M., Hasan, R., Shaikh, A. L., Hussain, S., \& Mazhar, W. (2019). Is Religiosity an Important Consideration in Muslim Consumer Behavior: Exploratory Study in the Context of Western Imported Food in Pakistan. Journal of Islamic Marketing, 10(04), 1288-1307.

Daniel, B. K. (2011). Handbook of Research on Methods and Techniques for Studying Virtual Communities: Paradigms and Phenomena. New York: United States of America byInformation Science Reference (an imprint of IGI Global).

Hasan, H. (2016). A Study on Awareness and Perception Towards Halal Foods A Muslim Students In Kota Kinibalu, Sabah. In Proceedings of the Australia-Middle East Conference on Business and Social Sciences 2016 (pp. 803-811). Dubai: in partnership with The Journal of Developing Areas, Tennessee State University, USA.

Ismoyowati, D. (2015). Halal Food Marketing: A Case Study on Consumer Behavior of Chicken-Based Processed Food Consumption in Central Part of Java, Indonesia. In Agriculture and Agricultural Science Procedia. Yogyakarta: The 2014 International Conference on Agro-industry (ICoA): Competitive and sustainable Agro-industry forHuman Welfare.

Jacoby, J., Troutman, T., Kuss, A., \& Mazursky, D. (1986). Experience and Expertise in Complex Decision Making. ACR North American Advances, 13, 469-472.

Kaiser, T., \& Menkhoff, L. (2017). Does Financial Education Impact Financial Literacy and Financial Behavior, and If So, When? The World Bank Economic Review, 31(03), 611630. 
Komariah, K., \& Subekti, P. (2016). Penggunaan Media Massa Sebagai Agen Sosialisasi Dinas Kesehatan Kabupaten Tasikmalaya dalam meningkatkan Kesadaran Masyarakat akan pentingnya Imunisasi. PRofesi Humas: Jurnal Ilmiah Ilmu Hubungan Masyarakat, 01(01), 76-90.

Kozinets, R. V. (1998). On Netnography: Initial Reflections on Consumer Research Investigations of Cyberculture. Advances in Consumer Research, 25, 366-371.

Kozinets, R. V, Valck, K. de, Wojnicki, A. C., \& Wilner, S. J. S. (2010). Networked Narratives: Understanding Word-of-Mouth Marketing in Online Communities. Journal of Marketing, 74(02), 71-89.

Kurniawati, D. A., \& Savitri, H. (2019). Awareness Level Analysis of Indonesian Consumers toward Halal Products. Journal of Islamic Marketing, 11(01), 522-546.

Lin, L., \& Chen, C. (2006). The Influence of the Country-of-Origin Image, Product Knowledge and Product Involvement on Consumer Purchase Decisions: An Empirical Study of Insurance and Catering Services in Taiwan. Journal of Consumer Marketing, 23(05), $248-265$.

Maharani, L., \& Mustika, M. (2016). Hubungan Self Awareness dengan Kedisiplinan Peserta Didik Kelas VIII di SMP Wiyatama Bandar Lampung (Penelitian Korelasional Bidang BK Pribadi). KONSELI: Jurnal Bimbingan Dan Konseling, 03(01), 17-31.

Moschis, G., \& Churchill, G. (1978). Consumer Socialization: A Theoretical and Empirical Analysis. Journal of Marketing Research, 15(04), 599-609.

Nasrullah, R. (2017). Etnografi Virtual (Riset Komunikasi, Budaya, dan Sosioteknologi di Internet). Bandung: Simbiosa Rekatama Media.

Notoatmodjo, S. (2003). Pendidikan dan Perilaku Kesehatan. Jakarta: Rineka Cipta.

Nurhayati, T., \& Hendar. (2019). Personal Intrinsic Religiosity and Product Knowledge on Halal Product Purchase Intention: Role of Halal Product Awareness. Journal of Islamic Marketing, 11(09), 603-620.

Nyota, H. (2016). The Impact of Socialization Agents on The Financial Behaviour of University Students in Zimbabwe. Midlands State University.

Purwanto, E., \& Ilhalauw, J. J. O. . (2017). Bisikan dari Balik Layar: Netnografi Strategi Bisnis Berorientasi Pasar. Journal of Business \& Applied Management, 09(02), 220-233.

Qardhawi, M. Y. (1980). Halal dan Haram dalam Islam. Singapura: Himpunan Belia Islam.

Reuters, T., \& Standard Dinar. (2018). State of the Global Islamic Economy Report 2018/2019. Dubai.

Rohmatun, K. I., \& Dewi, C. K. (2017). Pengaruh Pengetahuan Dan Religiusitas Terhadap 
Niat Beli Pada Kosmetik Halal Melalui Sikap. Ecodemica: Jurnal Ekonomi, Manajemen \& Bisnis Universitas Bina Sara Informatika, 01(01), 27-35.

S. Soesilowati, E. (2009). Peluang Usaha Produk Halal di Pasar Global: Perilaku Konsumen Muslim dalam Konsumsi Makanan Halal. Jakarta: Pusat Penelitian Ekonomi Lembaga Ilmu Pengetahuan Indonesia.

Sandra, L. J. (2013). Political Branding Jokowi Selama Masa Kampanye Pemilu Gubernur DKI Jakarta 2012 di Media Sosial Twitter. Jurnal E-Komunikasi, 01(02), 276-287.

Setyaningsih, E. D., \& Marwansyah, S. (2019). The Effect of Halal Certification and Halal Awareness through Interest in Decisions on Buying Halal Food Products. Syi'ar Iqtishadi: Journal of Islamic Economics, Finance and Banking, 03(01), 64-79.

Siswanto, T. (2013). Optimalisasi Sosial Media Sebagai Media Pemasaran Usaha Kecil Menengah. Jurnal Liquidty, 02(01), 80-86.

Soesilowati, E. S., \& Yuliana, C. I. (2013). Komparasi Perilaku Konsumen Produk Halal di Area Mayoritas dan Minoritas Muslim. Jurnal Ekonomi Dan Pembangunan, 21(02), 167178.

Sohn, S.-H., Joo, S.-H., Grable, J. E., Lee, S., \& Kim, M. (2012). Adolescents' Financial Literacy: The Role of Financial Socialization Agents, Financial Experiences, and Money Attitudes in Shaping Financial Literacy Among South Korean Youth. Journal of Adolescence, 35(04), 969-980.

Solihat, M. (2008). Komunikasi Massa dan Sosialisasi. Mediator: Jurnal Komunikasi, 09(02), $105-112$.

Soon, J. M., \& Wallace, C. (2017). Application of Theory of Planned Behaviour in Purchasing Intention and Consumption of Halal Food. Nutrition \& Food Science, 47(05), 635-647.

Sunarto, K. (2004). Pengantar Sosiologi. Jakarta: Lembaga Penerbit Fakultas Ekonomi Universitas Indonesia.

Tajuddin, M., \& Manan, A. (2017). Model Pemasaran Usaha Mikro Kecil Dan Menengah (Umkm) Berbasis Online Dalam Mendukung Pariwisata. MATRIK: Jurnal Manajemen, Teknik Informatika, Dan Rekayasa Komputer, 17(01), 66-74.

Wilson, J. A. J., \& Liu, J. (2011). The Challenges of Islamic Branding : Navigating Emotions And Halal. Journal of Islamic Marketing, 02(01), 28-42.

Yasid, Farhan, F., \& Andriansyah, Y. (2016). Factors Affecting Muslim Students Awareness of Halal Products in Yogyakarta, Indonesia. International Review of Management and Marketing, 06(48), 27-31.

Yunus, N. S. N. M., Rashid, W. E. W., Ariffina, N. M., \& Rashid, N. M. (2014). Muslim's Purchase Intention towards Non-Muslim's Halal Packaged Food Manufacturer. Procedia 
Miftakhul Khasanah, Peranan Media Sosial ......

- Social and Behavioral Sciences, 130, 145-154.

Zulaekah, S., \& Kusumawati, Y. (2005). Halal dan haram makanan dalam islam. Suhuf, 17(01), $25-35$.

154 |AL-TIJARY, Vol. 5, No. 2, Juni 2020 


\section{LAMPIRAN}

\section{Lampiran 1}

\section{Hasil Pencarian data Komunitas Virtual 'Halal'di Instagram}

\begin{tabular}{|r|l|r|l|r|l|}
\hline No & \multicolumn{1}{|c|}{ Akun } & Followers & Tanggal Bergabung & $\begin{array}{c}\text { Total } \\
\text { Jumlah } \\
\text { Postingan }\end{array}$ & Negara \\
\hline 1 & Halalcorner & 80.600 & 12 Oktober 2013 & 895 & Indonesia \\
\hline 2 & Anca.id & 26.500 & 22 Mei 2016 & 969 & Indonesia \\
\hline 3 & Halal.indonesia & 489 & Tidak ada Keterangan & 41 & Indonesia \\
\hline 4 & Halalexpo.id & 7.378 & Tidak ada Keterangan & 114 & Indonesia \\
\hline 5 & Halalindonesia & 17.700 & 6 Maret 2014 & 1.004 & Indonesia \\
\hline 6 & Halaltrip & 17.100 & 11 September 2013 & 1.226 & Indonesia \\
\hline 7 & Halalorharam1 & 14.700 & Tidak ada Keterangan & 2.252 & Indonesia \\
\hline
\end{tabular}

Sumber : Data primer diolah 


\section{Lampiran 2}

\section{Hasil Pencarian data Komunitas Virtual 'Halal'di Facebook}

\begin{tabular}{|c|c|c|c|c|}
\hline No & Grup & $\begin{array}{l}\text { Jumlah } \\
\text { Anggota }\end{array}$ & Halaman & $\begin{array}{c}\text { Jumlah } \\
\text { Anggota }\end{array}$ \\
\hline 1 & Halal Corner & 11.654 & Have Halal, Will Travel & 375.000 \\
\hline 2 & $\begin{array}{l}\text { Have Halal, Will Travel } \\
\text { Community }\end{array}$ & 6.885 & Halal Indonesia & 64.000 \\
\hline 3 & Halal Jogja LPPOM MUI DIY & 42 & Must Be Halal & 20.000 \\
\hline 4 & Pasar Halal & 28.996 & Halal Corner & 30.000 \\
\hline 5 & $\begin{array}{l}\text { Wisata Halal Internasional / } \\
\text { Halal Trip }\end{array}$ & 1.125 & Halal Japan & 97.000 \\
\hline 6 & Halal Langsung Enak & 5.742 & Halal Navi & 92.000 \\
\hline 7 & Wisata Halal Erupa UK & 2.019 & Hlal Korea & 235.000 \\
\hline 8 & Halal Food in Japan & 4.300 & Halal Media Japan & 120.000 \\
\hline 9 & Halal Food Hunters Korea & 5.900 & Japan Halal TV & 137.000 \\
\hline 10 & Halal/Haram Sustenance & 14.000 & Halal Foods in Japan & 18.000 \\
\hline 11 & Halal in New Zealand & 8.700 & Halal & 151.000 \\
\hline 12 & Australian Halal Food Guide & 25000 & Halal Jokes & 29.000 \\
\hline 13 & Australia's Halal Food Forum & 7.400 & Nippon Asian Halal Association & 26.000 \\
\hline 14 & Halal Food in Australia & 20.000 & Halal Food & 1.500 \\
\hline 15 & $\begin{array}{l}\text { Halal Food Delivery Singapore } \\
\text { Authentic }\end{array}$ & 13.588 & Halal Humour & 797.000 \\
\hline 16 & $\begin{array}{l}\text { Global Halal Eateries Outside } \\
\text { Singapore }\end{array}$ & 9.304 & Halal Food Japan & 5.600 \\
\hline 17 & & & Halal Japan & 10.000 \\
\hline 18 & & & Halal Mart & 226 \\
\hline 19 & & & Halal Gourmet Japan & 26.000 \\
\hline 20 & & & Halal Trip & 666.000 \\
\hline 21 & & & Liburan Halal & 1.200 \\
\hline 22 & & & Halal or Haram & 232.000 \\
\hline 23 & & & Halal in Korea & 40.000 \\
\hline 24 & & & Kawasan Halal MUI Jakarta & 19.000 \\
\hline 25 & & & Halal Traveler & 4.000 \\
\hline 26 & & & Halal Local & 2.300 \\
\hline 27 & & & Kampus Manajemen Halal & 1.000 \\
\hline 28 & & & Produk Halal MUI & 2.000 \\
\hline 29 & & & Halal Expo Korea & 8.800 \\
\hline 30 & & & Halal Recipes Japan & 45.000 \\
\hline 31 & & & Kosmetik Halal & 2.000 \\
\hline 32 & & & Global Halalal Intitute & 1.800 \\
\hline 33 & & & Halal Food in Japan & 6.000 \\
\hline
\end{tabular}

Sumber : Data primer diolah 


\section{Lampiran 3}

Postingan Dengan Interaksi Terbanyak

\begin{tabular}{lccc}
\hline \multicolumn{1}{c}{ Postingan } & Tanggal & Like & Komentar \\
\hline $\begin{array}{l}\text { Dampak Mengkonsumsi } \\
\text { Barang Haram }\end{array}$ & $\begin{array}{c}\text { 7 Januari } \\
\text { Popok Bayi Halal dan }\end{array}$ & 1602 & 30 \\
$\begin{array}{l}\text { Masa kadaluarsa label } \\
\text { halal }\end{array}$ & 16 Januari & 1236 & 214 \\
$\begin{array}{l}\text { Rum dan Essence Rhum } \\
\text { dinyatakan Haram oleh }\end{array}$ & 12 Maret & 789 & 52 \\
$\begin{array}{l}\text { MUI } \\
\text { Gambar skema produk } \\
\text { dari babi dan produk } \\
\text { turunannya. }\end{array}$ & 28 Maret & 2650 & 150 \\
$\begin{array}{l}\text { Berbagai macam Nama } \\
\text { lain / Alias /Istilah } \\
\text { daging Babi dalam } \\
\text { komposisi makanan }\end{array}$ & 30 Maret & 4317 & 154 \\
$\begin{array}{l}\text { Hukum Bacon dan } \\
\text { penamaan bacon }\end{array}$ & 1 juni & 1665 & 107 \\
$\begin{array}{l}\text { Hukum Kopi dengan } \\
\text { Bahan Tambahan }\end{array}$ & 9 Juli 2019 & 1246 & 57 \\
\hline
\end{tabular}

Sumber : Data primer diolah 